simple and the redular teeth rectangular with both subtending and internal bracts, and a second in which the female genitalia are complex in that a bursa copulatrix is present and the radular teeth are either rounded or rectangular and lack subtending bracts.

The conservative anatomical picture displayed is in marked contrast to the diversity implied by the numerous genera among which the species are now distributed. Furthermore, the two anatomical categories which are distinguishable cross the generic lines of the schemes of classification proposed by Thiele ${ }^{4}$, Schilder and Schilder ${ }^{5}$, Steadman and Cotton ${ }^{6}$, and Allan ${ }^{3}$. These facts indicate that the numerous genera described primarily on the basis of shell characters are untenable.

I propose that only the genus Cypraea be retained for members of the subfamily Cypraeinae. This genus can be broadly described on the basis of both conchological and anatomical characters, and thus described becomes a useful and significant taxonomic category. It obviates burdening the literature with innumerable genera which cannot be definitively described on the basis of shell characters alone. Based on several features of the animal, it is significant when considered both in relation to other members of the family Cypraeidae and to the prosobranchs in general. Differences which do exist in radula and genitalia may be utilized in conjunction with certain conchological characters to describe subgenera at a later date.

Alison KaY

Dept. of Zoology and Entomology, University of Hawaii, Honolulu.

Aug. 6.

${ }^{1}$ Burch, J., Systematic Zoology, 5, 144 (1956)

2 Verdcourt, B., Nature, 178, 1414 (1956).

"Allan, J., "Cowry Shells of World Seas" (Melbourne House, 1956). 4 Thiele, J., Handbuch der Systematischen Weichtierkunde (1931).

s Schilder and Schilder, Proc. Malac. Soc., 23, 119 (1938-39).

- Steadman and Cotton, Rec. S. Austr. Mus., 8, 503 (1946).

\section{A Method for concentrating Pollen Grains and Small Fossil Remains from Fibrous Peats and Moss Polsters}

ONE of the greatest factors retarding palynological studies of Australian Quaternary deposits is the difficulty in obtaining fossil pollen in concentrations sufficiently high for statistical analyses.

A modification of the standard sieving technique for peats ${ }^{1}$ has been developed for extracting pollen and other small plant remains (for example, seeds, epidermal tissues and fungal fruiting bodies) from fibrous peats in Western Australia.

The method involves the use of small wire gauze tubes into which the peat is placed. The tubes are then boiled in 10 per cent alkali (potassium hydroxide) and as the peat digests, the pollen and other fine fragments pass through the meshes of the gauze, leaving the larger remains in the tube. The pollen fraction is then centrifuged and treated by the standard acetolysis and oxidation methods ${ }^{1,2}$. The plant remains retained in the tube are removed by inverting it in a small phial containing 20 per cent aqueous glycerine. A quick shake is sufficient to dislodge the residues, which can be stored for future examination. The gauze slug must be thoroughly cleaned before re-using and this is achieved with a bottle brush the bristles of which are trimmed to the same diameter as the gauze sieve tubes.

Three types of tube, made from brass gauze to withstand the alkali treatment, have been used and the method of construction is outlined below.

(a) For peats. Tube A. A small cylinder is made from a strip of 60 -mesh gauze approximately $25 \mathrm{~mm} . \times$ $27 \mathrm{~mm}$., and the seam soldered (rolling the gauze around a pencil makes a tube of convenient diameter). A gauze disk is then soldered to one end of the tube and a small rubber stopper fitted to the other.

Tube B. A slightly larger tube is made in the same way as $A$, using a strip of $35 \mathrm{~mm}$. $\times 40 \mathrm{~mm}$. 100-mesh gauze.

(b) For moss polsters. Tube $C$. A large tube is made using a strip (approximately $65 \mathrm{~mm}$. $\times 65 \mathrm{~mm}$.) of 60 -mesh gauze. This tube is particularly valuable where statistical comparisons of size are to be made between pollen grain and pollen preparations from anthers, where uniform treatments are essential.

The main advantage of sieving is that it allows the separation of the pollen from the larger organic fragments which break down during the later stages of treatment to residues which obscure and dilute the pollen. To test the value of the sieves described, three pollen preparations were made from the same peat specimen. The first, or control preparation, was treated by the standard alkali, acetolysis and oxidation methods. The second preparation was treated in the same manner as the control with the exception that the peat was placed inside tube $\boldsymbol{A}$ during the alkali treatment. In the third preparation, tube $A$ was placed inside tube $B$ for the alkali treatment. An estimate of the concentration of pollen in the preparations was made by counting the ratio of the frequency of pollen to non-pollen material encountered by a micrometer eyepiece mark in a series of ten transects across an $18-\mathrm{mm}$. square coverslip. By comparison with the control preparation, the 60-mesh cylinder gave a 600 per cent increase in pollen frequency while a 1,500 per cent increase was obtained by placing tube $A$ inside tube $B$.

When the peat was boiled directly inside the tube $B$ it tended to block the meshes, preventing the finer material from passing through. Thus the principle of the modified method is the same as in mechanical analyses, where the coarser fractions are removed before proceeding to successively finer fractions, and this process continued until the desired size is reached.

The advantages of the gauze tubes over the more conventional sieving techniques appear to be twofold. First, the filtering process combines boiling in alkali and filtering into a single operation. Thus only the volume necessary for the alkali treatment is required and the time-consuming washing of residues and reconcentration from the filtrate eliminated. Secondly, continuous agitation prevents the possibility of packing the larger residues against the gauze where they could act as a filter and prevent the pollen material from passing through the sieve meshes.

Department of Botany, University of Western Australia.

1 Erdtman, G., “An Introduction to Pollen Analysis" (Chronica Botanica Company, Waltham, Mass., 1943).

" Faegri, K., and Iversen. J., "Textbook of Modern Pollen Analysis" (Ejnar Munksgaard, Copenhagen, 1950). 